\title{
CLUSTERING POTENSI SUSU SAPI PERAH DI KABUPATEN BOYOLALI MENGGUNAKAN ALGORITMA K-MEANS
}

\author{
Riski Lunika Parmawati ${ }^{1)}$, Iwan Ady Prabowo ${ }^{2)}$, Teguh Susyanto ${ }^{3)}$ \\ ${ }^{1,2,3)}$ Program Studi Teknik Informatika, STMIK Sinar Nusantara \\ ${ }^{1)}$ riskilunika@gmail.com; ${ }^{2}$ iwanadyp@gmail.com; ${ }^{3)}$ teguhsusyanto@gmail.com
}

\begin{abstract}
Based on data of dairy milk cow in Animal Farms of Boyolali District, only shows total amount dairy milk cow in Boyolali District. So that Animal Farms of Boyolali District does not know which areas produce dairy milk cows with large numbers or small. Therefore, an algorithm is needed to facilitate the grouping of potentially dairy milk cow based on milk production data (liter), number of female dairy cows (how many), number of owners and year of production. In this research, using K-Means algorithm is used to grouping of potential dairy milk cow producing areas. By using K-Means aims in facilitating the classification of an area that has the greatest potential dairy milk cows, medium and small. The result is an illustration that shows the regional grouping based on dairy milk cow yields, which are 13 districts that have potency of dairy milk cow (cluster1), 28 district that have medium potency dairy cows producing (cluster2), and 28 districts less potential dairy milk cows (cluster3). For further research could be carried out the excavation process variation data variables that clustering results produced can be maximized.

Keyword: K-Means algorithm, clustering, data mining, dairy milk cows
\end{abstract}

\section{PENDAHULUAN}

Boyolali merupakan salah satu daerah di Provinsi Jawa Tengah yang dikenal sebagai kota susu karena memiliki potensi penghasil susu sapi perah yang produktif dan terbesar di Jawa Tengah. Sebagian besar wilayah Boyolali adalah dataran tinggi dengan udara yang sejuk sehingga sangat cocok sekali dijadikan sebagai tempat untuk budidaya sapi perah dengan ketinggian tempat antara 751500 mdpl dan rata-rata curah hujan sekitar $2.000 \mathrm{~mm} /$ tahun. Di Kabupaten Boyolali memiliki 19 Kecamatan dan yang berpotensi penghasil susu sapi perah ada 8 Kecamatan yaitu Kecamatan Ampel, Boyolali , Cepogo, Mojosongo, Musuk, Selo, Simo dan Teras. Dari data hasil susu sapi perah di Dinas Peternakan Kabupaten Boyolali pada tahun 2015 memiliki jumlah total sapi perah 86.363 ekor dengan hasil produksi susu sapi perah $45.544 .919 \mathrm{lt} / \mathrm{th}$.

Sebagian besar susu sapi perah di Boyolali digunakan sebagai bahan baku pembuatan keju, yoghurt, dodol susu dan didistribusikan di industri pengolahan susu (IPS) seperti Firisian Flag, Indo Milk, Citra Nasional dan masih banyak lainya yang membuat susu sapi perah terus mengalami peningkatan kebutuhan setiap tahunnya. Oleh karena itu untuk memenuhi kebutuhan konsumsi susu sapi perah khususnya Boyolali maupun Jawa Tengah dan industri pengolahan susu (IPS), Dinas Peternakan Boyolali berupaya untuk mengoptimalkan hasil produksi susu sapi perah dengan mengelompokkan daerah yang menghasilkan susu sapi perah di Kabupaten Boyolali . Selain itu juga perlu melakukan sentralisasi daerah penghasil susu sapi perah di Kabupaten Boyolali agar tidak terjadi kekurangan bahkan mengharuskan import dari luar negeri.

Berdasarkan masalah yang telah diuraikan diatas maka akan dibuat clustering potensi susu sapi perah di kabupaten Boyolali menggunakan algoritma K-Means, yang akan menggambarkan pengelompokan daerah berdasarkan hasil peternakan susu sapi perah dan diharapkan dapat membantu Dinas Pertanian untuk mengetahui daerah mana yang berpotensi menghasilkan susu sapi perah di Kabupaten Boyolali .

\section{TINJAUAN PUSTAKA}

\subsection{Peternakan}

Peternakan merupakan kegiatan mengembangbiakkan dan membudidayakan hewan ternak untuk mendapatkan manfaat dan hasil dari kegiatan tersebut. Peternakan tidak terbatas pada pemeliharaaan saja. Memelihara dan peternakan perbedaannya terletak pada tujuan yang ditetapkan. Tujuan peternakan adalah mencari keuntungan dengan penerapan prinsip-prinsip manajemen pada faktor-faktor produksi yang telah dikombinasikan secara optimal. Kegiatan di bidang peternakan dapat dibagi atas dua 
golongan, yaitu peternakan hewan besar seperti sapi, kerbau dan kuda, sedang kelompok kedua yaitu peternakan hewan kecil seperti ayam, kelinci [1].

\subsection{Sapi Perah}

Sapi perah merupakan hewan ternak sumber penghasil susu yang dibutuhkan oleh masyarakat. Ternak sapi perah dibudidayakan untuk menghasilkan susu yang memiliki nilai gizi tinggi. Sebagai salah satu sumber protein hewani, susu semakin dibutuhkan dalam rangka meningkatkan kualitas hidup dan kecerdasan masyarakat.

Sapi perah merupakan hewan ternak terpenting sebagai sumber daging, susu, tenaga kerja, dan kebutuhan lainnya. Sapi menghasilkan sekitar 45-55\% kebutuhan daging dunia, 95\% kebutuhan susu, serta $85 \%$ kebutuhan kulit. Sapi perah berasal dari famili Bovidae, seperti halnya bison, banteng, kerbau (Bubalus), kerbau afrika (Syncherus), dan anoa. Sapi perah dipelihara dengan tujuan utama untuk diambil susunya. Ada beragam jenis sapi perah unggul yang biasa diternakkan, antara lain Shorhorn, Holstein, Friesian, Jersey, Brown Swiss, Red Danish, dan Droughmaster [2].

\subsection{Betina Produksi}

Sapi perah dilihat dari segi produksi susu, seekor sapi perah dapat dianggap mencapai kedewasaan pada umur sekitar lima tahun. Antara periode umur 5 sampai 10 tahun, volume produksi susu dalam satu masa laktasi tidak banyak terdapat perbedaan. Pada periode tersebut, produksi susu tertinggi dicapai pada saat sapi perah telah mencapai umur 7-8 tahun. Setelah sapi perah mencapai umur 10 tahun, produksi susu mulai berkurang bahkan kadang-kadang diikuti adanya kesulitan-kesulitan dalam melahirkan.

Masa laktasi adalah periode dimana sapi sedang aktif berproduksi. Sapi mulai berproduksi setelah melahirkan anak. Kira kira setengah jam setelah sapi betina melahirkan, produksi susu sudah keluar. Saat itulah masa laktasi dimulai. Namun demikian, sampai dengan 4-5 hari pertama, produksi susu masih berupa kolostrum yang tidak boleh dikonsumsi manusia. Kolostrum tersebut khusus diberikan untuk pedet (anak sapi) karena kandungan zat-zat di dalamnya sangat sesuai untuk pertumbuhan dan kehidupan awal.

Masa laktasi dimulai sejak sapi itu berproduksi sampai masa kering tiba. Dengan demikian, masa laktasi berlangsung selama 10 bulan atau kurang lebih 309 hari. Hanya saja, masa laktasi yang berlangsung 309 hari tersebut diawali dengan produksi kolostrum selama 4-5 hari. Dengan demikian, produksi susu bisa berlangsung sekitar 305 hari [2].

\subsection{Data Mining}

Data mining adalah suatu metode pengolahan data untuk menemukan pola yang tersembunyi dari data tersebut. Hasil dari pengolahan data dengan metode data mining ini dapat digunakan untuk mengambil keputusan di masa depan. Data mining ini juga dikenal dengan istilah pattern recognition. Data mining merupakan metode pengolahan data berskala besar oleh karena itu data mining ini memiliki peranan penting dalam bidang industri, keuangan, cuaca, ilmu dan teknologi. Secara umum kajian data mining membahas metode-metode seperti, clustering, klasifikasi, regresi, seleksi variable, dan market basket analisis [3].

\subsection{Normalisasi}

Normalisasi adalah proses penskalaan nilai atribut dari data sehingga bisa jatuh pada range tertentu. Contoh, misalnya berkenaan dengan pencatatan tingkat kematian penduduk di Indonesia per bulannya berdasarkan jenis umur. Secara sederhana, disana ada 3 dimensi data, yaitu bulan (1-12), umur (0-150) misalnya, dan jumlah kematian (0-jutaan). Kalau dibentangkan range masing-masing dimensi, maka akan mendapatkan ketidakseimbangan range pada dimensi yang ketiga, yaitu jumlah kematian. Salah satu metode normalisasi adalah min-max. Min-Max merupakan metode normalisasi dengan melakukan transformasi linier terhadap data asli. Berikut ini adalah persamaan normalisasi min-max:

$$
\text { newdata }=\frac{(\text { data }-\min ) *(\text { newmax }- \text { newmin })}{(\max -\min )}+\text { newmin } \ldots
$$

\section{Dimana:}

newdata $=$ data hasil normalisasi

$\min =$ nilai minimum data per kolom

$\max =$ nilai maksimum data per kolom

newmin $=$ batas minimum yang diberikan

newmax $=$ batas maksimum yang diberikan

\subsection{Clustering}

Pada dasarnya clustering merupakan suatu metode untuk mencari dan mengelompokkan data yang memiliki kemiripan karakteriktik (similarity) antara satu data dengan data yang lain. Clustering merupakan salah satu metode data mining yang bersifat tanpa arahan (unsupervised), 
maksudnya metode ini diterapkan tanpa adanya latihan (training) dan tanpa ada guru (teacher) serta tidak memerlukan target output. Dalam data mining ada dua jenis metode clustering yang digunakan dalam pengelompokan data, yaitu hierarchical clustering dan non-hierarchical clustering [3].

\subsection{Clustering K-means}

$K$-means clustering merupakan salah satu metode data clustering non-hirarki yang mengelompokan data dalam bentuk satu atau lebih cluster/kelompok. Data - data yang memiliki karakteristik yang sama dikelompokan dalam satu cluster/kelompok dan data yang memiliki karakteristik yang berbeda dikelompokan dengan cluster/kelompok yang lain sehingga data yang berada dalam satu cluster/kelompok memiliki tingkat variasi yang kecil [4].

Langkah-langkah melakukan clustering dengan algoritma K-Means adalah sebagai berikut [3]:

a. Pilih jumlah cluster k.

b. Inisialisasi k pusat cluster ini bisa dilakukan dengan berbagai cara. Namun yang paling sering dilakukan adalah dengan cara random. Pusat-pusat cluster diberi nilai awal dengan angka-angka random.

c. Alokasikan semua data/ objek ke cluster terdekat. Kedekatan dua objek ditentukan berdasarkan jarak kedua objek tersebut. Demikian juga kedekatan suatu data ke cluster tertentu ditentukan jarak antara data dengan pusat cluster. Dalam tahap ini perlu dihitung jarak tiap data ke tiap pusat cluster. Jarak paling antara satu data dengan satu cluster tertentu akan menentukan suatu data masuk dalam cluster mana. Untuk menghitung jarak semua data ke setiap tiitk pusat cluster dapat menggunakan teori jarak Euclidean yang dirumuskan sebagai berikut: dimana:

$$
D(i, j)=\sqrt{\left(X_{1 i}-X_{1 j}\right)^{2}+\cdots+\left(X_{k i}-X_{k j}\right)^{2}} \cdots
$$

$D(i, j)=$ Jarak data ke $i$ ke pusat cluster $j$

$\mathrm{X}_{\mathrm{ki}}=$ Data ke $i$ pada atribut data ke $k$

$X_{k j}=$ Titik pusat ke $j$ pada atribut ke $k$

d. Hitung kembali pusat cluster dengan keanggotaan cluster yang sekarang. Pusat cluster adalah rata-rata dari semua data/ objek dalam cluster tertentu. Jika dikehendaki bisa juga menggunakan median dari cluster tersebut. Jadi rata-rata (mean) bukan satu-satunya ukuran yang bisa dipakai. e. Tugaskan lagi setiap objek memakai pusat cluster yang baru. Jika pusat cluster tidak berubah lagi maka proses clustering selesai. Atau, kembali ke langkah nomor 3 sampai pusat cluster tidak berubah lagi.

\subsection{Penelitian Terkait $K$-Means Clustering}

Penelitian sebelumnya terkait penerapan data mining clustering dengan algoritma $K$ Means antara lain:

Penelitian Lianna Falecia, (2014) yang berjudul "Penerapan Metode Clustering dengan K-Means Untuk Memetakan Potensi Tanaman Padi di Kota Semarang" membahas tentang pengelompokan daerah potensial penghasil padi di Provinsi Jawa Tengah berdasarkan hasil pertanian padi. Kemudian penelitian Elly Muningsih \& Sri Kiswati, (2015) yang berjudul "Penerapan Metode K-Means Untuk Clustering Produk Online Shop Dalam Penentuan Stok Barang" membahas tentang menentukan stok minimum tiap barang yang harus dipenuhi berdasarkan minat konsumen[5][6.

Dari kedua penelitian memiliki perbedaan yaitu pada objek yang diteliti dan variabel yang digunakan. Dalam penelitian Lianna Falecia menggunakan objek penelitian tanaman padi dengan variabel luas panen $(\mathrm{Ha})$, produksi (ton) dan tahun panen. Kemudian penelitian Elly Muningsih \& Sri Kiswati menggunakan objek penelitian stok barang pada online shop dengan variabel kode produk, jumlah transaksi, volume penjualan dan rata-rata penjualan. Oleh karena itu penulis menggembangkan penelitian dengan menggunakan objek penelitian susu sapi perah dengan variabel produksi susu sapi perah (liter), betina produksi (ekor) dan jumlah pemilik di Kabupaten Boyolali pada tahun 2015.

\section{METODE PENELITIAN}

Pada penelitian ini penulis menerapkan model SDLC (System Development Lyfe Cycle) dengan metode waterfall yaitu dengan tahapan analisa sistem, desain sistem, konstruksi, pengujian dan implementasi.

\subsection{Analisa Sistem}

Analisa ini terdiri dari metode pengumpulan data saat melakukan penelitian yang akan menghasilkan sumber data. Dalam metode pengumpulan data dilakukan dengan cara observasi, wawancara dan studi pustaka. 


\subsubsection{Metode Pengumpulan Data}

a. Observasi

Pengumpulan data dengan melakukan observasi di Dinas Peternakan Kabupaten Boyolali secara langsung.

\section{b. Wawancara}

Pengumpulan data yang dilakukan dengan mengajukan pertanyaan yang berkaitan dengan penelitian kepada pihak Dinas Peternakan Kabupaten Boyolali , KUD per Kecamatan di Kabupaten Boyolali , dan kelompok tani susu sapi perah.

\section{c. Studi Pustaka}

Studi pustaka dilakukan dengan cara mencari referensi atau teori mengenai klustering melalui buku - buku acuan jurnal jurnal ilmiah guna membangun aplikasi penerapan metode Clustering potensi susu sapi perah di Kabupaten Boyolali menggunakan algoritma $K$-Means.

\subsubsection{Sumber Data}

\section{a. Data Primer}

Data primer yang penulis ambil berupa nama kelurahan, jumlah sapi perah betina dewasa produksi, hasil produksi susu per tahun dan jumlah pemilik yang didapat melalui observasi dan wawancara kepada Dinas Peternakan Boyolali , KUD per Kecamatan di Kabupaten Boyolali, dan kelompok tani susu sapi perah.

\section{b. Data Sekunder}

Penulis mengumpulkan sejumlah informasi dengan cara melakukan penelitian kepustakaan yaitu mempelajari buku-buku, literature, dan artikel lainnya dari masalah yang berkaitan.

\subsection{Desain sistem}

Tahapan berupa penggambaran, perencanaan dan pembuatan dengan menyatukan beberapa elemen terpisah ke dalam satu kesamaan yang utuh untuk memperjelas bentuk sebuah sistem.

\section{a. UML}

Pada tahapan ini menggunakan UML (Unified Modeling Language) dengan melalui perancangan sistem usecase diagram,class diagram, sequence diagram dan activity diagram.

\section{b. K-Means Clustering}

Pada penelitian ini akan dibangun sistem yang dapat digunakan untuk Clustering potensi susu sapi perah di Kabupaten Boyolali menggunakan algoritma K-Means. Kemudian langkah selanjutnya melakukan proses pengelompokan data menggunakan algoritma
K-Means. Pengelompokan dibagi menjadi tiga kelompok dengan pusat awal mengambil tiga kelurahan di Kabupaten Boyolali secara acak.

\subsection{Konstruksi Sistem}

Perangkat lunak yang digunakan dalam membangun sistem dan perangkat keras yang digunakan untuk mengimplementasikan sistem ini.

\subsection{Pengujian Sistem}

Pengujian sistem yang akan dilakukan ada 2 tahap pengujian yaitu pengujian fungsionalitas menggunakan metode blackbox testing dan pengujian validitas.

\section{a. Pengujian Fungsionalitas}

Pengujian fungsionalitas dilakukan dengan menggunakan metode blackbox testing yaitu untuk mencari kesalahan dan kekurangan dari sistem yang telah dibuat untuk kemudian dilakukan perbaikan dan penyempurnaan sistem.

\section{b. Pengujian Validitas}

Pengujian Validitas dilakukan dengan cara membandingkan hasil dari perhitungan manual dengan hasil perhitungan dari aplikasi penerapan Clustering potensi susu sapi perah di Kabupaten Boyolali menggunakan algoritma K-Means yang telah dibangun.

\subsection{Implementasi}

Implementasi aplikasi penerapan Clustering potensi susu sapi perah di Kabupaten Boyolali menggunakan algoritma K-Means berupa aplikasi dekstop.

\section{PEMBAHASAN}

\subsection{Penerapan Algoritma K-Means}

Tabel 1 Data Penelitian

\begin{tabular}{|l|l|l|l|l|}
\hline $\begin{array}{c}\mathbf{N} \\
\mathbf{O}\end{array}$ & KELURAHAN & $\begin{array}{c}\text { PRODUK } \\
\text { SI SUSU } \\
\text { (liter) }\end{array}$ & $\begin{array}{c}\text { BETINA } \\
\text { PRODUK } \\
\text { SI } \\
\text { (ekor) }\end{array}$ & $\begin{array}{c}\text { PEMILI } \\
\mathbf{K} \\
\text { (orang) }\end{array}$ \\
\hline 1 & Bakulan & 28339 & 12 & 226 \\
\hline 2 & Banaran & 93483 & 39 & 44 \\
\hline 3 & Banyuanyar & 1280222 & 528 & 278 \\
\hline 4 & Brajan & 89874 & 37 & 25 \\
\hline 5 & Butuh & 456468 & 188 & 65 \\
\hline 6 & Cabeankunti & 278733 & 115 & 245 \\
\hline 7 & Candi & 811639 & 335 & 218 \\
\hline 8 & Candigatak & 557890 & 230 & 264 \\
\hline 9 & Cepogo & 139155 & 57 & 411 \\
\hline 10 & Gedangan & 557890 & 230 & 295 \\
\hline$\ldots$ & \multicolumn{1}{|c}{} & $\ldots$ & $\ldots$ & $\ldots$ \\
\hline
\end{tabular}

Setelah data didapat maka akan dilakukan normalisasi dengan melakukan proses penskalaan nilai atribut dari data agar data dapat diolah dalam satu formula. Dilakukan 
normalisasi karena satuan dari masingmasing data berbeda, dalam penelitian ini menggunakan range antara 1 sampai 10 . Misalnya untuk menormalisasikan data produksi susu pada Kelurahan Bakulan adalah sebagai berikut:

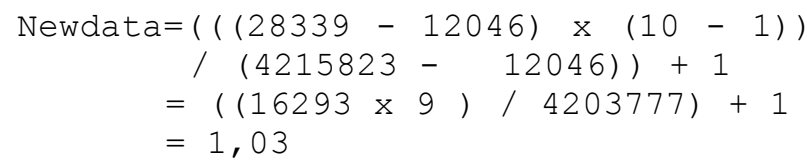

Menormalisasikan data betina produksi pada Kelurahan Bakulan :

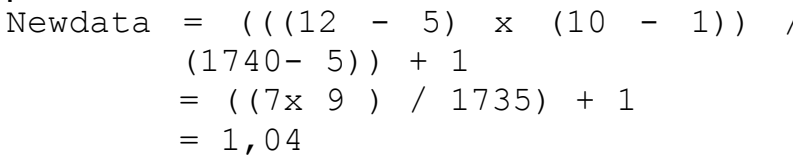

Menormalisasikan data pemilik pada Kelurahan Bakulan :

Newdata $=(((226-1) \times(10-1)) /$

$$
\begin{aligned}
& (849-1))+1 \\
& =((225 \times 9) / 848)+1 \\
& =3,39
\end{aligned}
$$

Berikut ini merupakan data yang sudah

\begin{tabular}{|c|c|c|c|c|}
\hline NO & KELURAHAN & $\begin{array}{l}\text { PROD. } \\
\text { SUSU }\end{array}$ & $\begin{array}{c}\text { BETINA } \\
\text { PRODUKSI }\end{array}$ & PEMILIK \\
\hline 1 & Bakulan & 1,03 & 1,04 & 3,39 \\
\hline 2 & Banaran & 1,17 & 1,18 & 1,46 \\
\hline 3 & Banyuanyar & 3,72 & 3,71 & 3,94 \\
\hline 4 & Brajan & 1,17 & 1,17 & 1,25 \\
\hline 5 & Butuh & 1,95 & 1,95 & 1,68 \\
\hline 6 & Cabeankunti & 1,57 & 1,57 & 3,59 \\
\hline 7 & Candi & 2,71 & 2,71 & 3,30 \\
\hline 8 & Candigatak & 2,17 & 2,17 & 3,79 \\
\hline 9 & Cepogo & 1,27 & 1,27 & 5,35 \\
\hline 10 & Gedangan & 2,17 & 2,17 & 4,12 \\
\hline
\end{tabular}
dinormalisasikan.

Tabel 2 Data Penelitian (2)

Data yang sudah di normalisasi akan diolah dengan algoritma K-Means untuk mengelompokan daerah yang berpotensi menghasilkan susu sapi perah di Kabupaten Boyolali. Adapun langkah dari pengelompokkan data sebagai berikut:

a. Untuk melakukan clustering dengan algoritma $K$-Means langkah yang pertama kali yaitu menentukan banyak cluster yang akan dibentuk. Pada penelitian ini, terdapat tiga cluster yaitu cluster $\mathrm{C} 1, \mathrm{C} 2, \mathrm{C} 3$.

b. Tentukan pusat cluster secara acak, dalam penelitian ini diambil pusat cluster awal, kelurahan Lanjaran sebagai $\mathrm{C} 1=(5,10$; 5,09; 4,46), kelurahan Mojosongo sebagai $\mathrm{C} 2=(2,18 ; 2,18 ; 4,06)$ dan kelurahan Bakulan sebagai $\mathrm{C} 3=(1,03 ; 1,04 ; 3,39)$.

c. Hitung jarak setiap data yang ada terhadap setiap pusat cluster. Misalkan untuk menghitung jarak data pertama dengan pusat cluster pertama adalah:

$$
d_{11}=\sqrt{(1,03-5,10)^{2}+(1,04-5,09)^{2}+(3,39-4,46)^{2}}
$$$$
=5,84
$$

Jarak data pertama dengan pusat cluster kedua:

$d_{12}=\sqrt{(1,03-2,18)^{2}+(1,04-2,18)^{2}+(3,39-4,06)^{2}}$

$$
=1,75
$$

Jarak data pertama dengan pusat cluster ketiga:

$$
\begin{gathered}
d_{13}=\sqrt{(1,03-1,03)^{2}+(1,04-1,04)^{2}+(3,39-3,39)^{2}} \\
=0,00
\end{gathered}
$$

dan seterusnya sampai data ke 69, kemudian hasil perhitungan di atas dimasukkan ke dalam tabel pusat cluster, sehingga diperoleh Tabel 3.

\section{Tabel 3 Hasil Perhitungan Jarak Cluster}

\begin{tabular}{|c|l|c|c|c|}
\hline NO & KELURAHAN & C1 & C2 & C3 \\
\hline 1 & Bakulan & 5,84 & 1,75 & 0,00 \\
\hline 2 & Banaran & 6,30 & 2,97 & 1,94 \\
\hline 3 & Banyuanyar & 2,02 & 2,17 & 3,83 \\
\hline 4 & Brajan & 6,41 & 3,15 & 2,14 \\
\hline 5 & Butuh & 5,24 & 2,40 & 2,15 \\
\hline 6 & Cabeankunti & 5,06 & 0,98 & 0,78 \\
\hline 7 & Candi & 3,56 & 1,07 & 2,37 \\
\hline 8 & Candigatak & 4,19 & 0,27 & 1,65 \\
\hline 9 & Cepogo & 5,48 & 1,82 & 1,99 \\
\hline 10 & Gedangan & 4,15 & 0,06 & 1,76 \\
\hline$\ldots$ & $\ldots$ & $\ldots$ & $\ldots$ & $\ldots$ \\
\hline
\end{tabular}

d. Suatu data akan menjadi anggota dari suatu cluster yang memiliki jarak terkecil dari pusat cluster-nya. Misalnya untuk data pertama, jarak terkecil diperoleh pada cluster ketiga, sehingga data pertama akan menjadi anggota dari cluster ketiga.

e. Hitung pusat cluster baru. Untuk cluster pertama, ada 12 data sehingga:

$$
\begin{gathered}
C_{11}=\frac{(3,72+\cdots+4,12)}{12}=5,00 \\
C_{12}=\frac{(3,71+\cdots+4,11)}{12}=4,993372 \\
C_{13}=\frac{(3,94+\cdots+8,40)}{12}=5,558373
\end{gathered}
$$

Untuk cluster kedua, ada 32 data sehingga:

$$
\begin{aligned}
& C_{21}=\frac{(2,71+\cdots+3,11)}{32}=2,253723 \\
& C_{22}=\frac{(2,71+\cdots+3,11)}{32}=2,253872 \\
& C_{23}=\frac{(3,30+\cdots+3,70)}{32}=4,362065
\end{aligned}
$$

Untuk cluster ketiga, ada 25 data sehingga:

$$
\begin{aligned}
& C_{31}=\frac{(1,03+\cdots+1,47)}{25}=1,306417 \\
& C_{32}=\frac{(1,04+\cdots+1,47)}{25}=1,306052 \\
& C_{33}=\frac{(3,39+\cdots+3,64)}{25}=2,515991
\end{aligned}
$$

f. Ulangi langkah 3 hingga posisi data sudah tidak mengalami perubahan. Dalam 
penelitian ini pada iterasi ke-3 dan iterasi ke-4 tidak terjadi perubahan. Kelompok atau cluster pertama terdapat 13 anggota, cluster kedua terdapat 28 anggota dan cluster ketiga terdapat 28 anggota.

Tabel 4 Posisi Cluster pada Iterasi ke-4

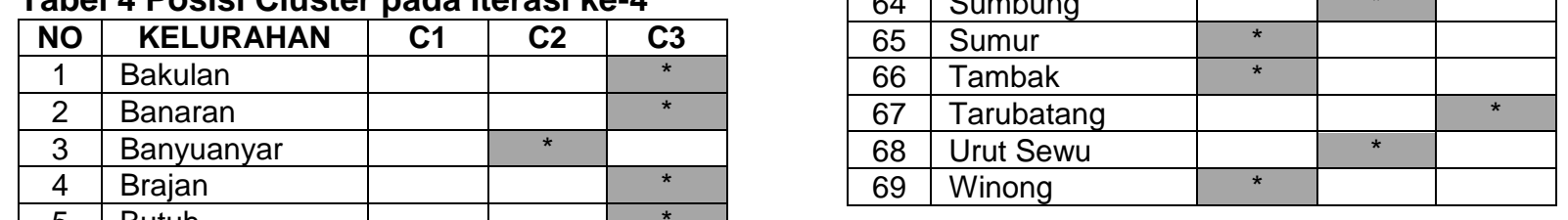

Pada Tabel 4 terlihat kelurahan yang termasuk pada cluster pertama (C1) ada 13 kelurahan yaitu Jemowo, Karangnongko, Kembang, Keposong, Lanjaran, Madu, Penggung, Samiran, Singosari, Sruni, Sumur, Tambak, Winong. Kelurahan yang termasuk pada cluster kedua (C2) ada 28 kelurahan yaitu Banyuanyar, Candi, Candigatak, Cepogo, Gedangan, Gubug, Jelok, Jeruk, Jlarem, Karanganyar, Karangkendal, Kembangkuning, Kembangsari, Kemiri, Kiringan, Lencoh, Mliwis, Mojosongo, Mudal, Musuk, Pagerjurang, Sangup, Selo, Sukabumi, Sukorame, Sukorejo, Sumbung, Urut Sewu. Dan kelurahan yang termasuk pada cluster ketiga (C3) ada 28 kelurahan yaitu Bakulan, Banaran, Brajan, Butuh, Cabeankunti, Genting, Jombong, Jrakah, Jurug, Kaligentong, Karanggeneng, Kebonbimo, Kebongulo, Kedunglengkong, Kragilan, Manggis, Metuk, Mojolegi, Nepen, Ngadirojo, Ngagrong, Ngargosari, Paras, Pusporenggo, Randusari, Seboto, Sudimoro, Tarubatang.

\subsection{Desain Sistem}

Tahap perancangan sistem ini menjelaskan model dari program yang dibangun, penulis menggunakan Unified Modeling Language (UML) yang terdiri dari usecase diagram, class diagram, sequence diagram dan activity diagram.

a. Usecase diagram

Gambar 1 memperlihatkan use case diagram sistem clustering potensi susu sapi perah dapat diilustrasikan bahwa pada sistem ini penulis hanya menggunakan aktor admin yang memiliki peran dan fungsi mengakses sistem, mengelola master data dan melakukan proses clustering, logout. 


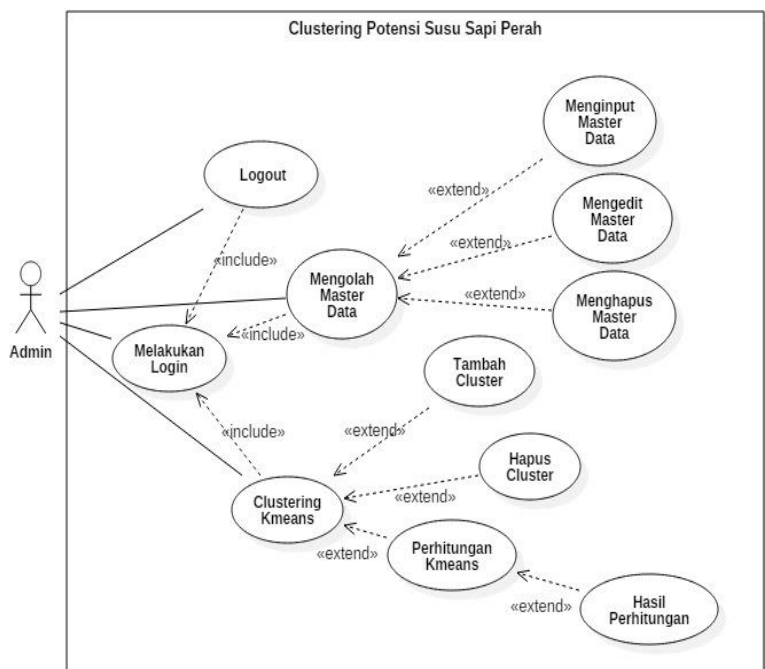

Gambar 1 Use Case Diagram Sistem Clustering Potensi Susu Sapi Perah

\section{b. Class Diagram}

Berikut class diagram dari sistem clustering potensi susu sapi perah di Kabupaten Boyolali menggunakan algoritma K-Means seperti yang terlihat pada Gambar 2.

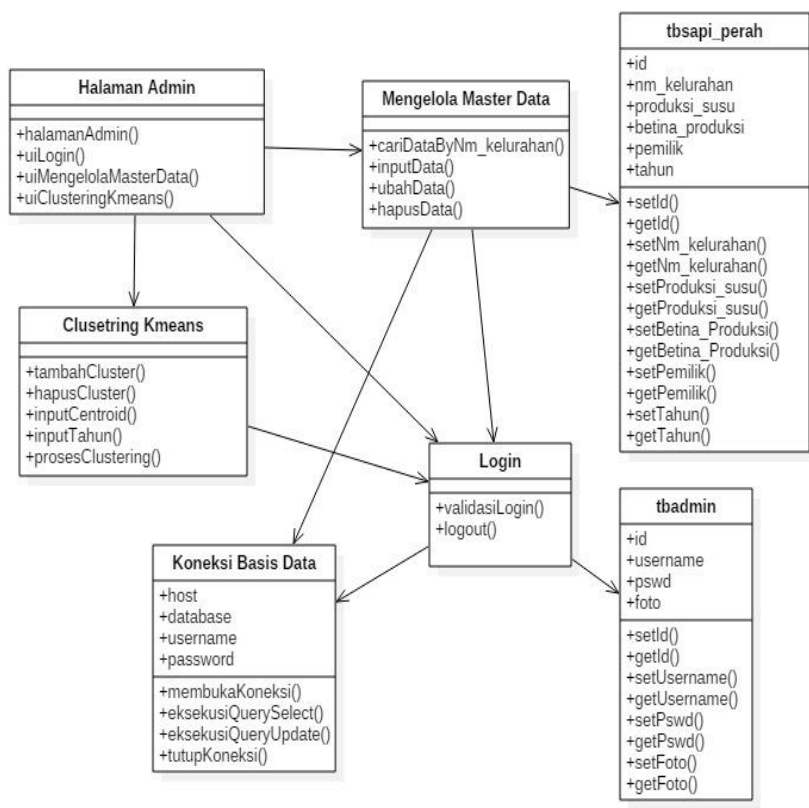

Gambar 2 Class Diagram Sistem Clustering Potensi Susu Sapi Perah

C. Sequence Diagram

Berikut ini gambar untuk sequence diagram perhitungan clustering K-Means yang terlihat seperti pada Gambar 3.

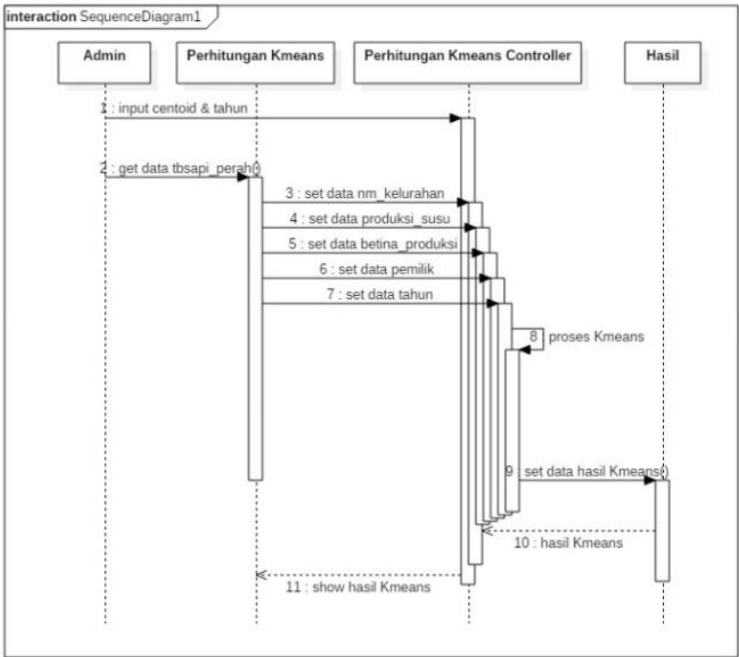

Gambar 3 Sequence Diagram Perhitungan Clustering K-Means

\section{d. Activity Diagram}

Cctivity diagram keseluruhan program seperti yang terlihat pada Gambar 4.

Ilustrasi activity diagram pada Gambar 4 mengenai clustering K-Means dapat dilihat pada deskripsi berikut. Dalam penelitian ini terdapat activity diagram melakukan login, menginput master data, mengedit master data, menghapus master data, melakukan logout.

Admin melakukan aktivitas dengan memilih menu clustering K-Means sistem akan menampilkan halaman clustering K-Means dan admin memasukkan centroid dan tahun kemudian menekan button proses clustering, maka secara otomatis sistem melakukan proses clustering dan admin memperoleh hasil clustering.

Admin melakukan aktivitas dengan menekan menu clustering K-Means untuk masuk ke halaman clustering dan setelah itu admin menekan button tambah cluster sistem akan menampilkan tambah cluster dengan menambah 1 baris form inputan cluster/ centroid awal.

Admin melakukan aktivitas dengan menekan menu clustering K-Means untuk masuk ke halaman clustering dan setelah itu admin menekan button hapus cluster sistem akan menampilkan hapus cluster dengan menghapus 1 baris form inputan cluster/ centroid awal. 


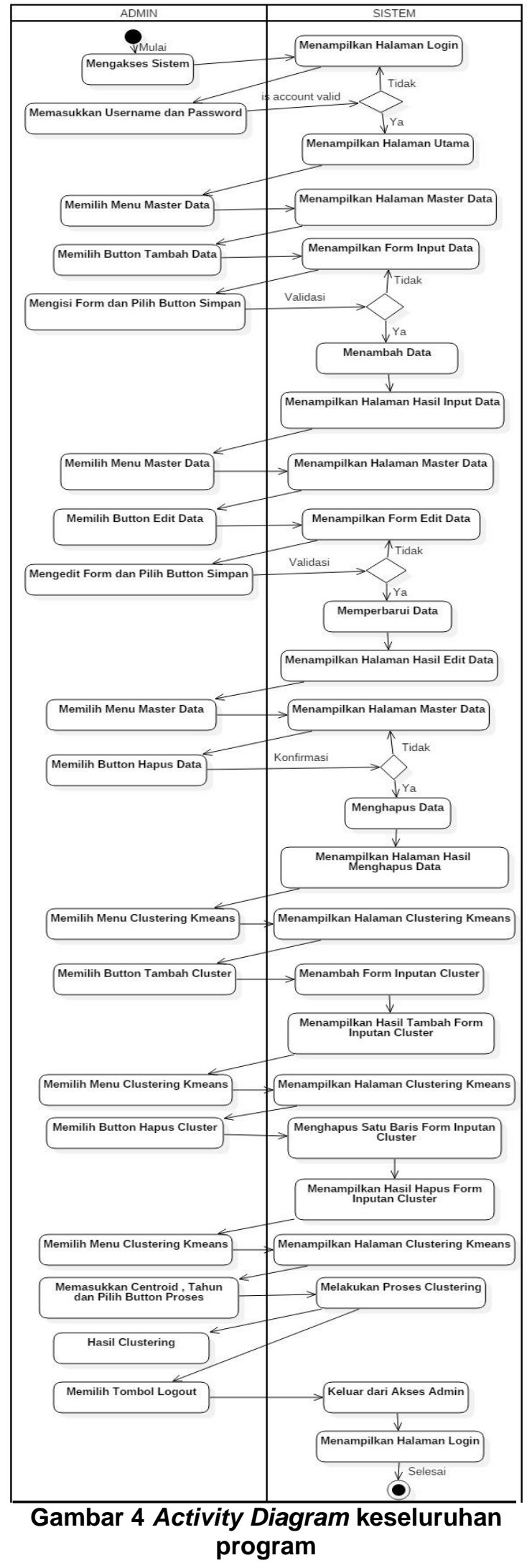

4.3 Pengujian Sistem

\section{a. Pengujian Validitas Sistem}

Hasil perhitungan manual dan excel dari data yang ada kemudian data diolah oleh sistem dengan menggunakan algoritma $K$ Means yang kemudian akan dibandingkan antara hasil perhitungan secara manual dengan perhitungan dengan sistem. Dalam penelitian ini dapat disimpulkan bahwa hasil perhitungan manual, excel dan menggunakan sistem menghasilkan hasil yang sama.

\section{b. Analisa Pengujian}

Dilihat dari hasil akhir antara perhitungan manual dengan perhitungan sistem, terdapat perbedaan jumlah angka di belakang koma. Hal ini dikarenakan adanya perbedaan floating ataupun pembulatan antara kedua perhitungan. Akan tetapi perbedaan tersebut masih dalam kondisi wajar sehingga masih dalam dapat di tolelir, sehingga dianggap hasil dari perhitungan manual dan perhitungan sistem adalah sama. Maka dapat ditarik kesimpulan bahwa sistem clustering potensi susu sapi perah di Kabupaten Boyolali ini sudah valid.

Untuk pengujian kesesuaian algoritma $K$ Means dengan kasus yang diangkat oleh penulis dengan cara membandingkan hasil akhir atau output dari sistem clustering potensi susu sapi perah di Kabupaten Boyolali pada tahun 2015 dengan data sebanyak 69 kelurahan di Boyolali . Sistem lama yang dipakai yaitu anggota KUD atau ketua kelompok susu sapi yang biasanya menangani tentang susu sapi perah dan mendata produksi susu sapi yang masuk. Data yang masuk dapat direkap dalam hitungan susu per hari, 10 hari dan hingga data 1 tahun. Karena terlalu sering menangani hal tentang persusuan sapi perah maka dari data tersebut anggota KUD atau ketua kelompok tani dapat mengetahui daerah mana yang berpotensi susu sapi perah banyak, sedang maupun sedikit. Dari sistem dengan hasil kenyataan yang sudah dilaksanakan terjadi perbedaan yaitu 18 kelurahan dari total data 69 kelurahan. Sehingga akurasi untuk pengujian pada tahun 2015 adalah sebesar 73,91\%

$$
\begin{gathered}
\text { Akurasi }=\frac{\text { total pengujian yang benar }}{\text { banyaknya data }} \times 100 \% \\
=\frac{51}{69} \times 100 \%=73,91 \%
\end{gathered}
$$

Sistem ini membagi clustering potensi susu sapi perah di Kabupaten Boyolali menjadi 3 cluster dan setelah dianalisa terdapat 13 daerah yang dikatakan berpotensi susu sapi perah banyak, 28 daerah yang dikatakan berpotensi susu sapi perah sedang, dan 28 daerah yang dikatakan berpotensi susu sapi perah sedikit dengan pusat cluster akhir yaitu pusat cluster 1 (4.8507692307692; 4.8476923076923; 5.7707692307692), pusat cluster 
2.1392857142857; 4.5532142857143), dan pusat cluster 3 (1.4914285714286; 1.4925; 2.3807142857143). Hasil clustering tersebut berdasarkan centroid/ pusat cluster yang dimasukkan, dalam penelitian ini centroid diambil secara acak dari data yang menggambarkan ketiga keadaan daerah tersebut. Dengan sistem ini bisa memperoleh daerah yang digunakan untuk sentralisasi produksi susu sapi perah di Kabupaten Boyolali agar produksi susu sapi perah optimal.

\subsection{Implementasi Antarmuka}

Aplikasi ini memiliki antar muka berupa tampilan desktop yang terdiri dari tampilan halaman admin, menu master data, tambah data, edit data, tambah cluster, hapus cluster dan berikut ini tampilan output untuk menu clustering K-Means, admin dapat menginputkan centroid awal dan tahun yang akan di cluster kemudian untuk melihat hasil clustering K-Meansnya bisa pilih button proses clustering seperti yang terlihat pada Gambar 5.

CLUSTERING POTENSI SUSU SAPI PERAH DI KABUPATEN BOYOLALI MENGGUNAKAN ALGORTIMA K-MEANS

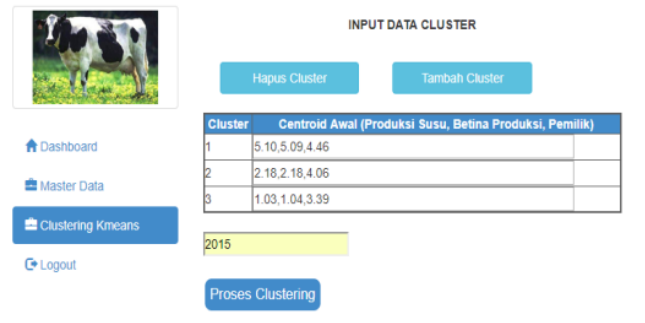

Gambar 5 Tampilan Menu Clustering K-Means

Berikut ini tampilan output untuk hasil perhitungan clustering K-Means dengan data yang telah diinputkan oleh admin seperti yang terlihat pada Gambar 6.

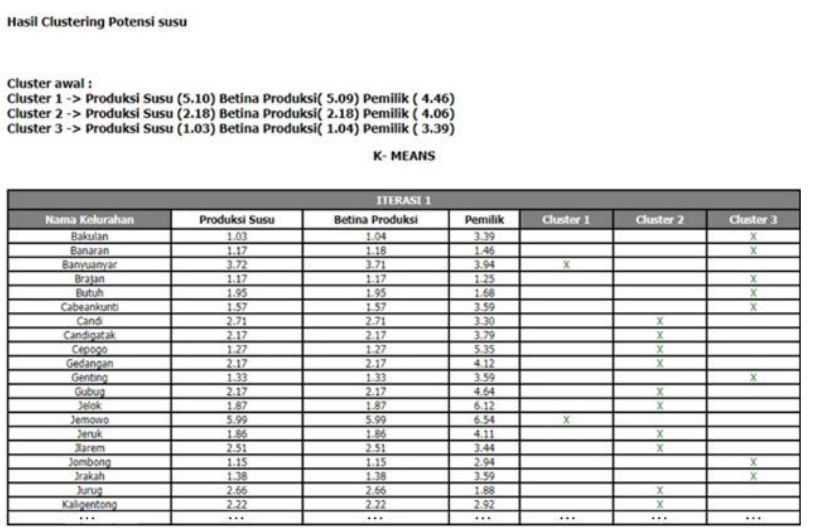

Gambar 6 Tampilan Hasil Perhitungan Clustering K-Means

\section{PENUTUP}

\subsection{Kesimpulan}

Ada beberapa hal yang dapat disimpulkan dari hasil penelitian dan pembuatan sebuah program aplikasi ini yaitu:

1. Algoritma K-Means dapat diterapkan pada clustering potensi susu sapi perah di Kabupaten Boyolali berdasarkan data yang ada untuk mengelompokan daerah-daerah yang memiliki kemiripan data yang sama.

2. Hasil cluster tidak dipengaruhi oleh nilai centroid awal yang dipakai namun dipengaruhi oleh jumlah data yang dipakai.

3. Akurasi untuk pengujian pada tahun 2015 adalah sebesar $73,91 \%$ yang menunjukkan bahwa program ini dapat dijadikan sebagai acuan dalam clustering potensi susu sapi perah di Kabupaten Boyolali .

4. Berdasarkan pengolahan data yang dilakukan dengan variabel data produksi susu, betina produksi dan pemilik menghasilkan 3 kelompok dengan 13 daerah yang berpotensi susu sapi perah banyak (cluster1), 28 daerah yang berpotensi susu sapi perah sedang (cluster2), dan 28 daerah yang berpotensi susu sapi perah sedikit (cluster3).

\subsection{Saran}

Saran-saran terhadap penggunaan sistem yang telah dibuat adalah sebagai berikut:

1. Perlu dilakukan proses penggalian variasi variabel data agar hasil clustering yang dihasilkan dapat lebih maksimal.

2. Aplikasi ini sebaiknya kedepanya bisa dikembangkan dengan hasil akhir yang dapat disimpan pada database.

3. Program yang telah dibuat masih cukup sederhana karena lebih mengutamakan inti dari proses perhitungan algoritma K-Means.

\section{DAFTAR PUSTAKA}

[1] Rasyaf, M., 1994, Manajemen Peternakan Ayam Kampung, Kanisius, Yogyakarta.

[2] Herlambang, B., 2014, Jadi Jutawan Dari Beternak Sapi Potong Dan Sapi Perah, FlashBooks, Jogjakarta.

[3] Santoso, B., 2007, Data Mining: Teknik Pemanfaatan Data untuk Keperluan Bisnis, Graha llmu, Yogyakarta.

[4] Agusta, Y., K-means - Penerapan, Permasalahan dan Metode Terkait, Jurnal Sistem dan Informatika, Vol. 3, 2007, https://yudiagusta.files.wordpress.c om/2008/03/k-means.pdf 
[5] Felicia, L., 2014, Penerapan Metode Clustering Dengan K-Means Untuk Memetakan Potensi Tanaman Padi Di Kota Semarang, diakses dari http://eprints.dinus.ac.id/13460/1/jurnal_1 4114.pdf.

[6] Muningsih, E. dan Kiswati, S., 2015, Penerapan Metode K-Means Untuk Clustering Produk Online Shop dalam Penentuan Stok Barang, Jurnal Bianglala Informatika, Vol 3 No 1, ejournal.bsi.ac.id/ejurnal/index.php/Biang lala/article/view/570. 